\section{Revista Brasileira de Administração Científica}

Brazilian Journal of Scientific Administration

Jul a Set 2020 - v.11 - n.3
ISSN: 2179-684X

\title{
Apropriação direta $\times$ rateio proporcional: aplicação nas empresas parcialmente submetidas à não cumulatividade
}

Esse estudo procura conhecer qual é o método predominantemente utilizado pelas pessoas jurídicas parcialmente submetidas à não cumulatividade na apuração do PIS/Pasep e da Cofins, e entender o motivo dessa escolha, entre a contabilidade de custo ou o rateio proporcional. A pesquisa está estruturada com o referencial teórico, considerando os métodos de custos e a forma de tributação das contribuições PIS/Pasep e a Cofins, seguido da exposição dos aspectos metodológicos com uma pesquisa qualitativa e descritiva. $O$ instrumento utilizado para a coleta dos dados é o questionário. Nessa linha, busca-se coletar informações sobre a realidade das empresas quanto o método adotado para registro dos custos a serem considerados na apuração do crédito tributário. 0 questionário formulado fo encaminhado para 24 profissionais, entre contadores internos de empresas e escritórios de contabilidade. A metade dos respondentes afirmou avaliar as vantagens e desvantagens de cada método, para cada empresa. A outra metade, que sempre utiliza o mesmo método, opta por utilizar o método do rateio proporcional. Os motivos que os levam a adoção desse método vão desde a agilidade na aplicação até a carência de informações de custos para sustentar a aplicação da apropriação direta pela contabilidade de custos. Dos entrevistados que aplicam sempre o método de rateio proporcional nas empresas que cuidam nenhum afirmou fazer uma análise de benefícios entre um método e outro. Esse resultado indica que, aparentemente, a utilização do rateio se dá mais por exclusão do que por vantajosidade do método.

Palavras-chave: Apropriação direta; Rateio proporcional; PIS/Pasep e Cofins.

\section{Direct appropriation x proportional apportionment: application in companies partially submitted to non-cumulative}

\begin{abstract}
This study seeks to find out which method is predominantly used by legal entities partially submitted to non-cumulative calculation of PIS/Pasep and Cofins, and to understand the reason for this choice, between cost accounting or proportional apportionment. The research is structured with the theoretical framework, considering the cost methods and the form of taxation of the PIS/Pasep and Cofins contributions, followed by the exposure of the methodological aspects with a qualitative and descriptive research. The instrument used for data collection is the questionnaire. In this line, we seek to collect information about the reality of companies regarding the method adopted to record the costs to be considered when calculating the tax credit. The questionnaire was sent to 24 professionals, including internal company accountants and accounting firms. Half of the respondents stated that they evaluated the advantages and disadvantages of each method, for each company. The other half, which always uses the same method, chooses to use the proportional apportionment method. The reasons that lead them to adopt this method range from agility in application to the lack of cost information to support the application of direct appropriation by cost accounting. Of the interviewees who always apply the proportional apportionment method in the companies they care for, none claimed to make a benefit analysis between one method and the other. This result indicates that, apparently, the use of apportionment occurs more by exclusion than by advantage of the method.
\end{abstract}

Keywords: Direct appropriation; Proportional apportionment; PIS/Pasep and Cofins.

Topic: Contabilidade de Custos

Reviewed anonymously in the process of blind peer.

Ana Paula Haskel (1D)

Universidade Federal de Santa Catarina, Brasil

http://lattes.cnpq.br/1285735936056598

http://orcid.org/0000-0002-2517-6147

anaphaskel@gmail.com

Camila Cristine da Silva Alves (ii)

Universidade Federal de Santa Catarina, Brasil

http://lattes.cnpq.br/2024126785949137

http://orcid.org/0000-0002-9604-9364

camilacsalves@gmail.com

Valdirene Gasparetto

Universidade Federal de Santa Catarina, Brasil http://lattes.cnpq.br/9876735629466934

http://orcid.org/0000-0002-2825-4067

valdirene.gasparetto@ufsc.br

d

DOI: 10.6008/CBPC2179-684X.2020.003.0018
Received: 05/06/2020

Approved: 30/07/2020
Referencing this:

HASKEL, A. P.; ALVES, C. C. S.; GASPARETTO, V.. Apropriação direta $x$ rateio proporcional: aplicação nas empresas parcialmente submetidas à não cumulatividade. Revista Brasileira de Administração Científica, v.11, n.3, p.258-274, 2020. DOI: http://doi.org/10.6008/CBPC2179$\underline{684 X .2020 .003 .0018}$ 


\section{INTRODUÇÃO}

Ao constituir uma pessoa jurídica, com finalidade econômica e lucrativa, há a obrigatoriedade da escolha tributária de cada empresa. Sem deixar de considerar as possibilidades e obrigações devidas pelo contribuinte, a atividade desenvolvida e o porte da empresa, inicialmente se tem as seguintes alternativas de regime tributário: Simples Nacional, Lucro Presumido, Lucro Arbitrado e Lucro Real.

Dentre essas alternativas, a única que se utiliza da contabilidade para fins de ajustes tributários na apuração do lucro é o Lucro Real. Nas demais formas tributárias, apesar da exigência em lei da escrituração contábil, conforme o artigo no 1.179 do Código Civil, a contabilidade não exerce nenhuma influência tributária.

Por opção ou por obrigatoriedade, quando há a escolha pelo regime de Lucro Real, a contabilidade possui influência significativa na apuração dos tributos, principalmente sobre o IRPJ, CSLL, PIS/Pasep e a Cofins. Os dois últimos são contribuições que, via de regra, possuem a mesma natureza, finalidade e forma de apuração; entretanto suas alíquotas são distintas. Na apuração dessas duas contribuições, a empresa do Lucro Real, em regra, deverá ser enquadrada no processo não cumulativo, o qual, resumidamente, possui a possibilidade do direito ao crédito e alíquotas majoradas.

Ocorre que, conforme o artigo no 10 da Lei n. 10.833/03, em algumas atividades, mesmo que a empresa opte pelo Lucro Real, quando a tratativa tributária são as contribuições PIS/Pasep e Cofins, a pessoa jurídica poderá estar submetida à cumulatividade. Sendo assim, há a possibilidade de uma mesma empresa estar enquadrada em duas formas diferentes de apuração do PIS/Pasep e da Cofins: pela sistemática cumulativa e pela sistemática não cumulativa. Isso acontecerá quando a empresa, por opção ou obrigatoriedade, estiver enquadrada no Lucro Real e uma das suas atividades estiverem listadas entre os incisos VII e XXX do artigo supracitado.

A pessoa jurídica enquadrada nessa situação deve registrar, a cada mês, o percentual de crédito conforme a opção tributária. Para aquelas submetidas ao regime simultâneo das contribuições, deverá destacar as parcelas dos custos, das despesas e dos encargos, como insumos, despesas de depreciação dos bens do ativo imobilizado necessários para execução da atividade da empresa, bem como demais despesas necessárias para execução da atividade, como energia elétrica, frete, alugueis pagos a outra pessoa jurídica, arrendamento mercantil, entre outras.

O valor a ser registrado deve ser determinado, a critério da pessoa jurídica, por um desses métodos: I - apropriação direta, inclusive em relação aos custos, por meio de sistema de contabilidade de custos integrada e coordenada com a escrituração; ou II - rateio proporcional, aplicando-se aos custos, despesas e encargos comuns a relação percentual existente entre a receita bruta sujeita ao regime de apuração não cumulativo e a receita bruta total, auferidas em cada mês.

Para apuração do crédito decorrente de encargos comuns, na hipótese do inciso I, devem ser aplicados sobre o valor de aquisição de insumos, dos custos e das despesas, referentes ao mês de apuração, critérios de apropriação por rateio que confiram adequada distribuição entre os encargos vinculados às 
receitas submetidas ao regime de apuração não cumulativa e os encargos vinculados às receitas submetidas ao regime de apuração cumulativa.

Para apuração do crédito decorrente de encargos comuns, na hipótese do inciso II, a receita bruta total objeto do rateio proporcional corresponderá à soma das receitas de venda de bens e serviços auferidas pela pessoa jurídica nas operações em conta própria ou alheia e todas as demais receitas auferidas pela pessoa jurídica, independentemente de sua denominação ou classificação contábil. A contabilidade possui vários métodos de custeio que podem ser aplicados a uma empresa. Souza (2011) afirma que "é o método de custeio que estabelece quais elementos de custo serão considerados na apuração do custo dos objetos de custeio".

Existem muitas críticas em relação aos métodos de custeio, principalmente aos tradicionais. Miler et al. (1985) afirmam que, no moderno ambiente produtivo, a utilização de métodos tradicionais de custeio oculta os altos custos indiretos dos departamentos de apoio em razão da utilização de rateios arbitrários baseados no volume. Esse efeito, os autores denominaram de 'fábrica oculta', já que os custos indiretos chegavam a representar uma segunda fábrica dentro da primeira. Apesar de existirem inúmeras formas gerenciais de registrar os custos nas empresas, tributariamente os custos restringem-se a valores bem específicos que podem ser demonstrados por meio da contabilidade.

Diante das possibilidades apresentadas, a pergunta que essa pesquisa busca responder é: $\mathrm{Na}$ sistemática da apuração simultânea do PIS/Pasep e da Cofins, qual o método de apropriação do direito ao crédito mais utilizado: apropriação direta ou rateio proporcional?. O objetivo deste trabalho é conhecer qual é o método predominantemente utilizado pelas pessoas jurídicas parcialmente submetidas à não cumulatividade na apuração do PIS/Pasep e da Cofins, e entender o motivo dessa escolha.

O presente estudo justifica-se pela importância da aproximação de questões práticas a questões teóricas, no sentido de enriquecer tanto a área tributária com pesquisas acadêmicas sobre o assunto, que podem colaborar para boas práticas dentro da empresa e tomadas de decisão mais assertivas economicamente, quanto o próprio ramo da ciência contábil, que carece de estudos voltados a área tributária, especificamente que relacionem questões tributárias e contabilidade. A pesquisa está estruturada da seguinte forma: No capítulo a seguir é apresentado o referencial teórico, seguido da exposição dos aspectos metodológicos. Na sequência, descreve-se os resultados e analisa-se dos dados. Por sim, apresentase as considerações finais.

\section{REVISÃO TEÓRICA}

\section{Contabilidade de custos}

De acordo com Martins (2008), a contabilidade de custos surgiu da necessidade de uma maior precisão no controle e identificação dos valores utilizados na produção. Assim, é o ramo da ciência contábil que registra, analisa e interpreta os gastos de produção de bens e serviços passíveis de serem avaliados, bem como controla os estoques, tudo para combater os gastos excedentes. Com o aumento da competitividade, 
as funções da contabilidade de custos passam a ser mais complexas e criteriosas: além do atendimento às necessidades fiscais, também atua no auxílio ao processo decisório dentro das entidades, dando estrutura e suporte à tomada de decisões gerenciais.

O preço de venda dos produtos e serviços é fixado pelas tendências de mercado, ou seja, a demanda é o fator determinante e não os custos de produção para a obtenção do bem ou prestação do serviço. Assim, é muito provável que uma empresa analise seus custos e suas despesas para verificar a viabilidade em trabalhar com um produto, cujo preço o mercado influencia marcantemente ou mesmo fixa, em vez de ela propriamente determinar o preço em função daqueles custos ou despesas (MARTINS, 2008). Informações contábeis são requeridas para o controle de custos e melhorias na produtividade. Dentro do controle dos custos, identificar os métodos de custeio existentes, e qual o mais adequado para a gestão da empresa é fator primordial para uma boa gestão empresarial.

\section{Métodos de custeio}

Existem vários métodos de custeio conhecidos que podem ser aplicados a uma empresa. Souza (2011) afirma que "é o método de custeio que estabelece quais elementos de custo serão considerados na apuração do custo dos objetos de custeio". Os sistemas de custos geram informações acerca da mensuração do custo dos objetos de custeio, ou seja, atribuem valor aos recursos utilizados na fabricação de bens ou prestação de serviços. Cada setor e atividade poderá se adequar a um método diferente para alcançar a melhor alternativa de mensuração dos valores em uma empresa.

Conforme o IFAC (1998) os métodos ou formas de custeio podem ser classificados em quatro estágios, nos quais em cada um existe uma ênfase maior em relação a cada método de custeio. Encontramse no primeiro estágio os métodos de custeio Padrão, Absorção, Variável e ROI; no segundo estágio, os métodos de Preço de Transferência, Moeda Constante; Valor Presente e Orçamento; no terceiro estágio temse a utilização com mais ênfase do método ABC; Custeio de Meta, Benchmarking, Just in Time, Gestão Baseada em Atividades, Kaizen e a utilização do Planejamento Estratégico; ao final, no quarto estágio, encontram-se os métodos EVA, Simulação, BSC, VBM e GECON.

Observa-se que não necessariamente trata-se de métodos de custeio, mas formas de identificar, com uma categoria diferenciada, o custo dos produtos nas empresas. Existem críticas em relação aos métodos de custeio, principalmente aos tradicionais. Miler et al. (1985), no moderno ambiente produtivo, criticavam a utilização de métodos tradicionais de custeio pois, segundo os autores, estes ocultavam os altos custos indiretos dos departamentos de apoio, pela utilização de rateios arbitrários baseados no volume; a essa situação, os autores denominaram "fábrica oculta", já que, segundo eles, os custos indiretos chegavam a representar uma segunda fábrica dentro da primeira. Graças ao avanço da tecnologia e do gerenciamento das informações de custos, novas formas de produção de bens e serviços surgem. A diversificação dos produtos e dos serviços também se apresenta cada vez mais acentuada, conforme IFAC (1998).

Miller et al. (1985) explicam que negócios estão gradualmente trocando pessoas por máquinas e, em algumas companhias de alta tecnologia, a mão de obra direta pode representar não mais que $5 \%$ dos custos. 
Nesse sentido, os autores defendem que os custos/despesas indiretas assumiriam um valor crescente em relação aos demais custos e a dificuldade em distribuí-los aos objetos de custos inviabilizaria a forma tradicional de custeio. Como o objetivo desse estudo não é tratar de todos os métodos, escolheu-se alguns para destacar.

\section{Custeio por absorção}

Kaplan et al. (1998) explicam que o custeio por absorção consiste na apropriação de todos os custos de produção aos bens elaborados (e só os de produção). Portanto, todos os gastos relativos ao esforço de produção são distribuídos para todos os produtos ou serviços realizados. Alvares (2011) complementa ao descrever que no custeio por absorção, os custos são alocados aos produtos se utilizando uma base de volume, usualmente o volume de horas de mão de obra direta.

O custeio por absorção, por ser um método pelo qual são utilizados rateios para alocação dos custos, pode gerar informações imprecisas e distorcidas, pela própria natureza de invariabilidade dos custos fixos, arbitrariedade em seu rateio e pela variação por unidade em função de oscilações no volume global (MARTINS, 2008). Apesar disso, é obrigatório pela legislação fiscal, excetuados alguns casos isolados.

\section{Custeio variável}

Diante das fragilidades do método de Custeio por Absorção, em são proporcionados "valores de lucro não muito úteis para fins decisoriais" (MARTINS, 2008), criou-se um método alternativo: o Custeio Variável. Conforme explica Souza (2011), no método de custeio variável (ou direto) não há rateio para apropriação dos custos fixos; esses passam a ser considerados despesas do período. Somente os custos variáveis são apropriados aos produtos. Apesar de trazer informações úteis para tomada de decisão, a utilização desse método é aceitável apenas para fins gerenciais. Ao final do período, as empresas fazer uma adaptação para o método de Custeio por Absorção, a fim de cumprirem com as exigências da legislação.

\section{Custeio ABC}

Padoveze (2009) salienta que, ao se alocar os custos indiretos fixos, tem-se uma forte probabilidade de distorcer as informações dos custos dos produtos. Com intuito de reduzir informações inadequadas, aponta a viabilidade da metodologia do Custeamento por Atividades ( $A B C)$. O método de custeio $A B C$, conforme explicado por Martins (2008), “é uma ferramenta que permite melhor visualização dos custos através da análise das atividades executadas dentro da empresa e suas respectivas relações com os produtos". Apesar do sistema ABC não atender às exigências fiscais, é uma ferramenta bastante precisa na mensuração dos custos por relacionar suas atividades aos produtos e recursos. Todavia, diante de sua complexidade, geralmente a sua utilização não é feita por empresas pequenas.

Cada método de custeio tem sua utilidade; seja para efeitos fiscais, com a utilização do Custeio por Absorção, seja para o acesso de informações gerenciais mais estratégicas, como podem apresentar o Custeio Variável, $\mathrm{ABC}$ ou qualquer outro. A escolha do método de custeio é particular para cada empresa e depende 
do tipo de atividade e conveniência de cada uma.

\section{Tributo}

O sistema tributário nacional é regido pelo disposto na Emenda Constitucional № 18 , de 1 o de dezembro de 1965, em leis complementares, em resoluções do Senado Federal e, nos limites das respectivas competências, em leis federais, nas Constituições e em leis estaduais e municipais. Considera-se tributo, conforme o Código Tributário Nacional (CTN), toda prestação pecuniária compulsória, em moeda ou cujo valor nela se possa exprimir, que não constitua sanção de ato ilícito, instituída em lei e cobrada mediante atividade administrativa plenamente vinculada. São classificados como tributos: impostos, taxas e contribuições de melhoria. Estes tributos são segregados por tributos federais, estaduais e municipais.

\section{Contribuições Sociais: PIS/PASEP E COFINS}

O Programa de Integração Social (PIS) e o Programa de Formação do Patrimônio do Servidor Público (PASEP), mais conhecidos como PIS/PASEP, são contribuições sociais de natureza tributária, devidas pelas pessoas jurídicas, com objetivo de financiar o pagamento do seguro-desemprego, abono e participação na receita dos órgãos e entidades para os trabalhadores públicos e privados, constituídos pelas Leis Complementares no 7/1.970 e a no 8/1.970 respectivamente. A Contribuição para o Financiamento da Seguridade Social (COFINS) é uma contribuição federal, de natureza tributária, incidente sobre a receita bruta das empresas em geral, destinada também a financiar a seguridade social, instituída pela Lei Complementar ำ 70/1991.

O Programa de Integração Social (PIS) e o Programa de Formação do Patrimônio do Servidor Público (PASEP) foram instituídos pela Lei Complementar no 7 e pela de $\mathrm{n} 08$ de 1970, respectivamente. Podemos observar que se trata de uma legislação complexa, esparsa e consideravelmente instável, não sendo muito diferente da contribuição para o financiamento da Seguridade Social (COFINS), instituída pela Lei Complementar no 70 de 1991. A Lei n. 9.718/1998 instituiu o Regime Cumulativo para apuração do PIS/PASEP e da COFINS para todas as empresas optantes pelo regime do Lucro Presumido e para empresas enquadradas no Lucro Real.

Posteriormente, houve a publicação da Lei no 10.637/2002, que trouxe a sistemática não cumulativa para fins de cálculo do PIS/PASESP. No ano seguinte, com a publicação da Lei no 10.833/2003, a sistemática não cumulativa se estendeu para o cálculo da COFINS para todas as empresas enquadradas no Lucro Real, com algumas exceções, que estão listadas no artigo $8^{\circ}$ da Lei no 10.637/2002 e no artigo 10 da Lei no 10.833/2003. Na sequência, em 2014, foi publicada a Lei no 12.973, que veio restabelecer novos critérios para base de cálculo dessas contribuições. Em 2017, a Instrução Normativa n. 1.700 consolidou diversas situações em torno do assunto.

Conforme prevê o artigo 149 da Constituição Federal, compete exclusivamente à União instituir contribuições sociais, de intervenção no domínio econômico e de interesse das categorias profissionais ou econômicas, como instrumento de sua atuação nas respectivas áreas, observado o disposto nos artigos 146, 
inciso III, e 150, incisos I e III, e sem prejuízo do previsto no artigo 195, § 6ㅇ, relativamente às contribuições.

A própria Constituição Federal define que as contribuições sociais e de intervenção no domínio econômico:

I - não incidirão sobre as receitas decorrentes de exportação;

II - incidirão também sobre a importação de produtos estrangeiros ou serviços;

III - poderão ter alíquotas:

a) ad valorem, tendo por base o faturamento, a receita bruta ou o valor da operação e, no caso de importação, o valor aduaneiro;

b) específica, tendo por base a unidade de medida adotada.

A pessoa natural destinatária das operações de importação poderá ser equiparada à pessoa jurídica, na forma da lei.

A lei definirá as hipóteses em que as contribuições incidirão uma única vez. (BRASIL, 1988)

O artigo 195 da Constituição Federal descreve que a seguridade social será financiada por toda a sociedade, de forma direta e indireta, nos termos da lei, mediante recursos provenientes dos orçamentos da União, dos Estados, do Distrito Federal e dos Municípios, e das seguintes contribuições sociais:

I - do empregador, da empresa e da entidade a ela equiparada na forma da lei, incidentes sobre:

a) a folha de salários e demais rendimentos do trabalho pagos ou creditados, a qualquer título, à pessoa física que lhe preste serviço, mesmo sem vínculo empregatício;

b) a receita ou o faturamento;

c) o lucro;

II - do trabalhador e dos demais segurados da previdência social, não incidindo contribuição sobre aposentadoria e pensão concedidas pelo regime geral de previdência social que trata o art. 201 da Constituição Federal;

III - sobre a receita de concursos de prognósticos.

IV - do importador de bens ou serviços do exterior, ou de quem a lei a ele equiparar. (BRASIL, 1988)

Ressalta-se que as contribuições sociais só poderão ser exigidas depois de decorridos noventa dias da data da publicação da lei, que as houver instituído ou modificado, aplicando-se o princípio da noventena. A própria Constituição Federal define que as contribuições sociais previstas poderão ter alíquotas ou bases de cálculo diferenciadas, em razão da atividade econômica, da utilização intensiva de mão de obra, do porte da empresa ou da condição estrutural do mercado de trabalho.

\section{Regimes de Apuração}

Como definido na Constituição Federal, as contribuições poderão ter alíquotas ad valorem, tendo por base o faturamento, a receita bruta ou o valor da operação e, no caso de importação, o valor aduaneiro, com as Leis Ordinárias publicadas posteriormente, os enquadramentos tributários foram segregados em das formas de apuração do PIS/PASEP e da COFINS: o regime cumulativo e o regime não-cumulativo.

\section{Regime Cumulativo}

No regime cumulativo, em todas as etapas há a incidência tributária sem considerar a etapa anterior. 
Para isso, considera-se o efeito de tributação como cascata, conforme definido por Ferraz Junior (2000). 0 principal identificador dos tributos cumulativos é repetir sobre bases de cálculo que, por superposição em cascata, tornam-se cada vez mais elevadas pela adição de novas margens de lucro, de novas despesas acessórias e do próprio tributo incidente sobre operações posteriores.

Entretanto, sempre se faz necessário fazer um estudo tributário, avaliando as vantagens e desvantagens de cada regime para uma tomada de decisão coerente com cada empresa em estudo. Estão enquadradas na apuração cumulativa, por exemplo, as empresas enquadradas tributariamente no Lucro Presumido, as entidades imunes, e no sistema simplificado de tributação - Simples Nacional. Há também situações específicas das empresas no Lucro Real, previstas no artigo 10 da Lei no 10.833/03 como também no artigo 8 da Lei no 10.637/02.

\section{Regime Não Cumulativo}

O regime não cumulativo foi instituído pela Lei no $10.637 / 2002$, que prevê inicialmente a não cumulatividade para o PIS/PASEP. Posteriormente, a Lei no 10.833/2003 trouxe a não cumulatividade também para a COFINS. $\mathrm{O}$ artigo primeiro das legislações mencionadas prevê que a contribuição para o PIS/PASEP e COFINS, com a incidência não cumulativa, incide sobre o total das receitas auferidas no mês pela pessoa jurídica, independentemente de sua denominação ou classificação contábil.

Assim, o total das receitas compreende a receita bruta de que trata o art. 12 do Decreto-Lei no 1.598, de 26 de dezembro de 1977, e todas as demais receitas auferidas pela pessoa jurídica com os respectivos valores decorrentes do ajuste a valor presente de que trata o inciso VIII do caput do art. 183 da Lei no 6.404, de 15 de dezembro de 1976. Neste regime podemos observar maior complexidade de apuração das contribuições, e é na apuração não cumulativa que existe a possibilidade de apuração do direito ao crédito na entrada de bens para revenda, insumos, como também em outros itens que podem disponibilizar este percentual de crédito.

Para melhorar a compreensão do conceito de receita bruta, segue a definição contábil de receita trazida pelo Comitê de Pronunciamentos Contábeis (CPC), por meio do Pronunciamento Conceitual Básico: 'Receitas são aumentos nos benefícios econômicos durante o período contábil, sob a forma da entrada de recursos ou do aumento de ativos ou diminuição de passivos, que resultam em aumentos do patrimônio líquido, e que não estejam relacionados com a contribuição dos detentores dos instrumentos Patrimoniais'.

A definição de receita abrange tanto receitas propriamente ditas quanto ganhos. 'A receita surge no curso das atividades usuais da entidade e é designada por uma variedade de nomes, tais como vendas, honorários, juros, dividendos, royalties, aluguéis'. 'Ganhos representam outros itens que se enquadram na definição de receita e podem ou não surgir no curso das atividades usuais da entidade, representando aumentos nos benefícios econômicos e, como tais, não diferem, em natureza, das receitas'. 'Ganhos incluem, por exemplo, aqueles que resultam da venda de ativos não circulantes'.

Salientando que as pessoas jurídicas de direito privado e as que thes são equiparadas pela legislação do imposto de renda, que apuram o IRPJ com base no Lucro Real, estão sujeitas à incidência não cumulativa, 
exceto as pessoas jurídicas elencadas no artigo 10 da Lei 10.833/2003 e no artigo $8^{\circ}$ da Lei n. 10.637/02.

\section{Pessoas Jurídicas não Abrangidas Pela Não Cumulatividade}

Permanecem sujeitas às normas da legislação da contribuição para o PIS/PASEP e COFINS, vigentes à cumulatividade:

I - no caso de bancos comerciais, bancos de investimentos, bancos de desenvolvimento, caixas econômicas, sociedades de crédito, financiamento e investimento, sociedades de crédito imobiliário, sociedades corretoras, distribuidoras de títulos e valores mobiliários, empresas de arrendamento mercantil e cooperativas de crédito; a securitização de créditos; as operadoras de planos de assistência à saúde;

II - as pessoas jurídicas tributadas pelo imposto de renda com base no lucro presumido ou arbitrado;

III - as pessoas jurídicas optantes pelo Simples;

IV - as pessoas jurídicas imunes a impostos;

V - os órgãos públicos, as autarquias e fundações públicas federais, estaduais e municipais, e as fundações cuja criação tenha sido autorizada por lei, referidas no art. 61 do Ato das Disposições Constitucionais Transitórias da Constituição de 1988;

$\mathrm{VI}$ - sociedades cooperativas, exceto as de produção agropecuária e as de consumo;

VII - as receitas decorrentes das operações:

a) sujeitas à substituição tributária da contribuição para o PIS/PASEP e da Cofins;

b) as pessoas jurídicas que tenham como objeto social, declarado em seus atos constitutivos, a compra e venda de veículos automotores poderão equiparar, para efeitos tributários, como operação de consignação, as operações de venda de veículos usados, adquiridos para revenda, bem assim dos recebidos como parte do preço da venda de veículos novos ou usados;

Os veículos usados serão objeto de Nota Fiscal de Entrada e, quando da venda, de Nota Fiscal de Saída, sujeitando-se ao respectivo regime fiscal aplicável às operações de consignação.

VIII - as receitas decorrentes de prestação de serviços de telecomunicações;

IX - as receitas decorrentes de venda de jornais e periódicos e de prestação de serviços das empresas jornalísticas e de radiodifusão sonora e de sons e imagens;

$X$ - as pessoas jurídicas integrantes do Mercado Atacadista de Energia Elétrica (MAE), instituído pela Lei $n^{\circ} 10.433 / 02$, poderá optar por regime especial de tributação, relativamente à contribuição para o Programa de Integração Social e de Formação do Patrimônio do Servidor Público (PIS/PASEP) e à Contribuição para o Financiamento da Seguridade Social (COFINS);

A opção pelo regime especial MAE:

a) será exercida mediante simples comunicado, nos termos e condições estabelecidos pela Secretaria da Receita Federal;

b) produzirá efeitos em relação aos fatos geradores ocorridos a partir do mês subsequente ao do exercício da opção.

$\mathrm{XI}$ - as receitas relativas a contratos firmados anteriormente a 31 de outubro de 2003:

a) com prazo superior a 1 (um) ano, de administradoras de planos de consórcios de bens móveis e imóveis, regularmente autorizadas a funcionar pelo Banco Central;

b) com prazo superior a 1 (um) ano, de construção por empreitada ou de fornecimento, a preço predeterminado, de bens ou serviços;

c) de construção por empreitada ou de fornecimento, a preço predeterminado, de bens ou serviços contratados com pessoa jurídica de direito público, empresa pública, sociedade 
de economia mista ou suas subsidiárias, bem como os contratos posteriormente firmados decorrentes de propostas apresentadas, em processo licitatório, até aquela data;

XII - as receitas decorrentes de prestação de serviços de transporte coletivo rodoviário, metroviário, ferroviário e aquaviário de passageiros;

XIII - as receitas decorrentes de serviços:

a) prestados por hospital, pronto-socorro, clínica médica, odontológica, de fisioterapia e de fonoaudiologia, e laboratório de anatomia patológica, citológica ou de análises clínicas; e

b) de diálise, raios $X$, radiodiagnóstico e radioterapia, quimioterapia e de banco de sangue; XIV - as receitas decorrentes de prestação de serviços de educação infantil, ensinos fundamental e médio e educação superior;

$\mathrm{XV}$ - as receitas decorrentes de vendas de mercadorias realizadas pelas pessoas jurídicas estabelecidas na zona primária de porto ou aeroporto poderão ser autorizadas, nos termos e condições fixados pelo Ministro de Estado da Fazenda, o funcionamento de lojas francas para venda de mercadoria nacional ou estrangeira à passageiros de viagens internacionais, na chegada ou saída do País, ou em trânsito, contra pagamento em moeda nacional ou estrangeira;

$\mathrm{XVI}$ - as receitas decorrentes de prestação de serviço de transporte coletivo de passageiros, efetuado por empresas regulares de linhas aéreas domésticas, e as decorrentes da prestação de serviço de transporte de pessoas por empresas de táxi aéreo;

XVII - as receitas auferidas por pessoas jurídicas, decorrentes da edição de periódicos e de informações neles contidas, que sejam relativas aos assinantes dos serviços públicos de telefonia;

XVIII - as receitas decorrentes de prestação de serviços com aeronaves de uso agrícola inscritas no Registro Aeronáutico Brasileiro (RAB);

XIX - as receitas decorrentes de prestação de serviços das empresas de callcenter, telemarketing, telecobrança e de teleatendimento em geral;

XX - as receitas decorrentes da execução por administração, empreitada ou subempreitada, de obras de construção civil;

XXI - as receitas auferidas por parques temáticos, e as decorrentes de serviços de hotelaria e de organização de feiras e eventos, conforme definido em ato conjunto dos Ministérios da Fazenda e do Turismo;

XXII - as receitas decorrentes da prestação de serviços postais e telegráficos prestados pela Empresa Brasileira de Correios e Telégrafos;

XXIII - as receitas decorrentes de prestação de serviços públicos de concessionárias operadoras de rodovias;

XXIV - as receitas decorrentes da prestação de serviços das agências de viagem e de viagens e turismo;

XXV - as receitas auferidas por empresas de serviços de informática, decorrentes das atividades de desenvolvimento de software e o seu licenciamento ou cessão de direito de uso, bem como de análise, programação, instalação, configuração, assessoria, consultoria, suporte técnico e manutenção ou atualização de software, compreendidas ainda como softwares as páginas eletrônicas;

XXVI - as receitas relativas às atividades de revenda de imóveis, desmembramento ou loteamento de terrenos, incorporação imobiliária e construção de prédio destinado à venda, quando decorrentes de contratos de longo prazo firmados antes de 31 de outubro de 2003;

XXIX - as receitas decorrentes de operações de comercialização de pedra britada, de areia para construção civil e de areia de brita;

XXX - as receitas decorrentes da alienação de participações societárias.

Portanto, todas as atividades listadas neste tópico, por mais que empresa esteja enquadrada no 
Lucro Real, o PIS/PASEP e a COFINS, permanecem com as alíquotas da sistemática cumulativa.

\section{Créditos apurados no Mercado Interno}

O direito ao crédito nasce com a aquisição, em cada mês, de bens e serviços que, na fase anterior da cadeia de produção ou de comercialização, sujeitaram-se às contribuições. Assim, as vendas efetuadas com suspensão, isenção, alíquota zero ou não incidência do PIS/PASEP e da COFINS não impedem a manutenção, pelo vendedor, dos créditos vinculados a essas operações.

Considerando que o direito ao crédito será sobre as alíquotas básicas, do valor das contribuições a pagar, a pessoa jurídica pode descontar créditos, determinados mediante a aplicação das seguintes alíquotas sobre a base de cálculo dos créditos de: a) PIS/PASEP - 1,65\% (um inteiro e sessenta e cinco centésimos por cento); b) COFINS - 7,6\% (sete inteiros e seis por cento).

\section{Apuração Proporcional de Créditos}

No caso de custos, despesas e encargos vinculados às receitas não cumulativas e àquelas submetidas ao regime de incidência cumulativa dessa contribuição, o crédito será determinado, a critério da pessoa jurídica, pelo método de: A apropriação direta, inclusive em relação aos custos, por meio de sistema de contabilidade de custos integrada e coordenada com a escrituração; ou O rateio proporcional, aplicando-se aos custos, despesas e encargos comuns a relação percentual existente entre a receita bruta sujeita à incidência não cumulativa e a receita bruta total, auferidas em cada mês.

Na hipótese de a pessoa jurídica sujeitar-se ao regime de apuração não cumulativa da Contribuição para o PIS/Pasep e da Cofins, em relação a apenas parte de suas receitas, o crédito deve ser calculado, exclusivamente, em relação aos custos, despesas e encargos vinculados a essas receitas. Onde a pessoa jurídica deve registrar, a cada mês, destacadamente para a modalidade de incidência referida no caput e para aquelas submetidas ao regime de incidência cumulativa dessa contribuição, as parcelas: I - dos custos, das despesas e dos encargos; e II - do custo de aquisição dos bens e serviços.

O valor a ser registrado deve ser determinado, a critério da pessoa jurídica, pelo método de: I apropriação direta, inclusive em relação aos custos, por meio de sistema de contabilidade de custos integrada e coordenada com a escrituração; ou II - rateio proporcional, aplicando-se aos custos, despesas e encargos comuns à relação percentual existente entre a receita bruta sujeita ao regime de apuração não cumulativa e a receita bruta total, auferidas em cada mês. O método eleito pela pessoa jurídica deve ser aplicado consistentemente por todo o ano-calendário, tendo de ser o mesmo para a Contribuição para o PIS/Pasep e para a Cofins.

\section{METODOLOGIA}

A seguir, são apresentados aspectos de caracterização da pesquisa e dos instrumentos utilizados para a coleta dos dados. 


\section{Caracterização da pesquisa}

A pesquisa é caracterizada como qualitativa e descritiva. Segundo Gil (1999), pesquisas descritivas servem para encontrar e descrever características de certa população. Neste estudo, busca-se conhecer o método predominantemente utilizado para registro dos custos na apuração dos créditos de PIS/Pasep e Cofins pelas empresas parcialmente sujeitas ao regime não cumulativo. $O$ autor também explica que estudos classificados sob este título possuem como característica mais significativa a utilização de técnicas padronizadas de coleta de dados.

\section{Instrumento para coleta de dados}

O instrumento utilizado para a coleta dos dados é o questionário, técnica de investigação composta por um número mais ou menos elevado de questões apresentadas por escrito às pessoas, que tem por objetivo o conhecimento de opiniões, crenças, sentimentos, etc. (Gil, 1999). Nessa linha, busca-se coletar informações sobre a realidade das empresas quanto o método adotado para registro dos custos a serem considerados na apuração do crédito tributário.

O questionário formulado, composto por 8 (oito) questões, entre perguntas abertas e fechadas, dicotômicas e de múltipla escolha, foi encaminhado para 24 profissionais, entre contadores internos de empresas e escritórios de contabilidade. O encaminhamento do questionário aos destinatários é feito via $e$ mail e o questionário é disponibilizado na plataforma SurveyMonkey ${ }^{\circledR}$ por 30 dias.

São os escritórios de contabilidade e/ou contadores os responsáveis pelo preenchimento das questões, indicando a opção de método a ser aplicado no registro dos custos e a motivação para tal escolha. Após o prazo estabelecido, apurou-se quais foram os questionários respondidos e retornados para análise qualitativa das respostas, a fim de conhecer quais métodos são adotados nas empresas.

\section{RESULTADOS E DISCUSSÃO}

\section{Apresentação dos dados}

Entre os 24 possíveis participantes, entre profissionais contábeis e escritórios de contabilidade, 14 retornaram o questionário preenchido. A primeira pergunta buscou conhecer o local de exercício da atividade do respondente, se contador dentro de uma empresa ou em um escritório de contabilidade.

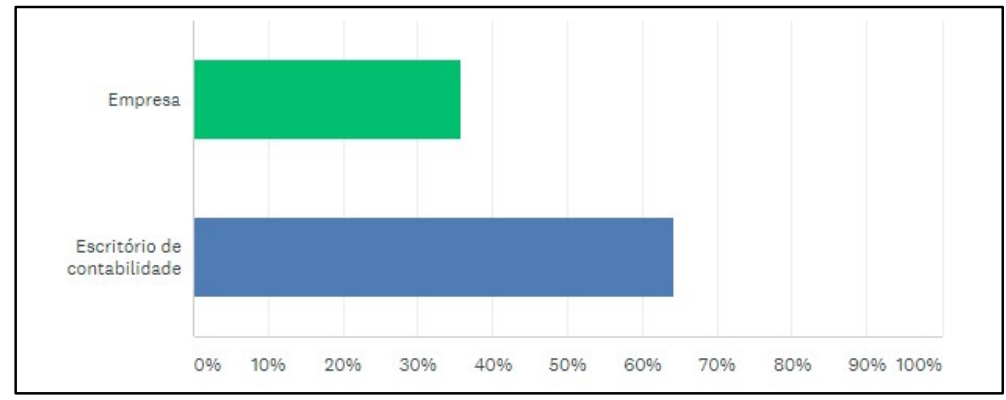

Figura 1: Resultado do questionário.

Pode-se observar que entre os que participaram da pesquisa, 35,71\% são contadores de empresas e 
64,29\% exercem atividade dentro de escritórios de contabilidade. Questionados sobre a região de atuação, 71\% exerce atividade no estado de Santa Catarina, seguido por Pernambuco, Minas Gerais e São Paulo. Dos 14 participantes da pesquisa, apenas 6 fazem a contabilidade de pelos uma empresa enquadrada no Lucro Real que, simultaneamente, possui a apuração cumulativa e não cumulativa dentro da mesma empresa, conforme o artigo 10 da Lei no 10.833/03, para a apuração do PIS/Pasep e Cofins, e trouxeram informações acerca da forma de apuração de 12 empresas.

Essas empresas estão espalhadas por diversos estados do Brasil: Santa Catarina, Rio Grande do Sul, Goiás, Maranhão, Minas Gerais, Pernambuco, São Paulo e Tocantins. Apesar das poucas empresas existentes nessa situação apresentada, foram alcançados dados de empresas de todas as regiões do país. Questionados sobre se sentirem aptos para analisar todas as possibilidades de crédito de PIS/Pasep e da COFINS quando, simultaneamente, a empresa possui atividades cumulativas e não cumulativas, a maioria dos respondentes julga-se, sob uma análise pessoal, parcialmente apto.

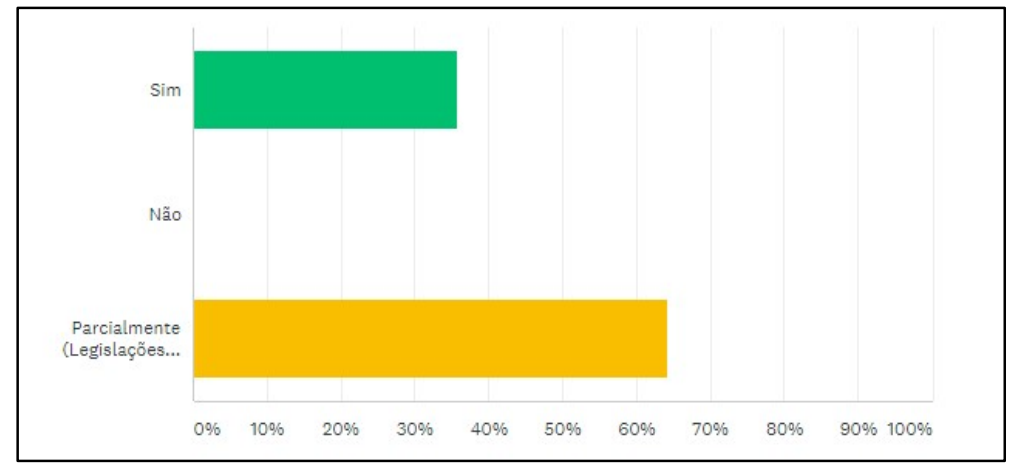

Figura 2: Resultado do questionário.

Aproximadamente $64 \%$ dos participantes não se sentem confortáveis devido vária situações inerentes a área tributária, como por exemplo a falta de clareza na legislação, interpretações divergentes sobre o mesmo assunto. Em contrapartida, 36\% dos profissionais se sentem confortáveis na análise dessa situação. Em relação à adoção do critério de escolha (a apropriação direta em relação aos custos, por meio de sistema de contabilidade de custos, ou rateio proporcional) para reconhecimento de gastos em comum (custos, despesas e encargos), quando questionados se é sempre o mesmo para todas as empresas enquadradas em regime cumulativo e não cumulativo, as respostas foram divididas.

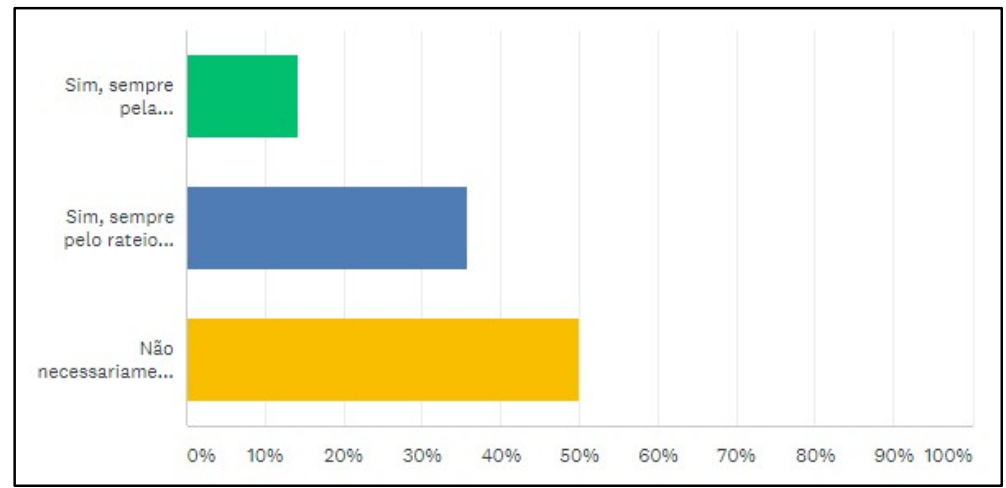

Figura 3: Resultado do questionário.

Metade dos respondentes indicaram que sempre analisam as vantagens de cada método. Entre os 
que utilizam sempre o mesmo método, a maioria (36\% do total) opta pelo rateio proporcional enquanto $14 \%$ sempre fazem pela apropriação direta, na apuração das contribuições. As duas últimas questões buscaram compreender os motivos pelos quais os profissionais são levados a optar por cada método.

Acerca dos fatores que os levam a adotar o método do rateio proporcional para a apropriação do direito ao crédito do PIS/Pasep e da Cofins, 21\% adota em decorrência da agilidade no processo de apuração do crédito; o mesmo percentual utiliza porque as empresas não possuem contabilidade de custos adequada à realidade; $14,29 \%$ pelo fato de que a empresa não possui contabilidade de custos e 7,14\% identificaram outros motivos. O restante, $35,71 \%$, afirmou que não utiliza esse método para apropriação do direito ao crédito.

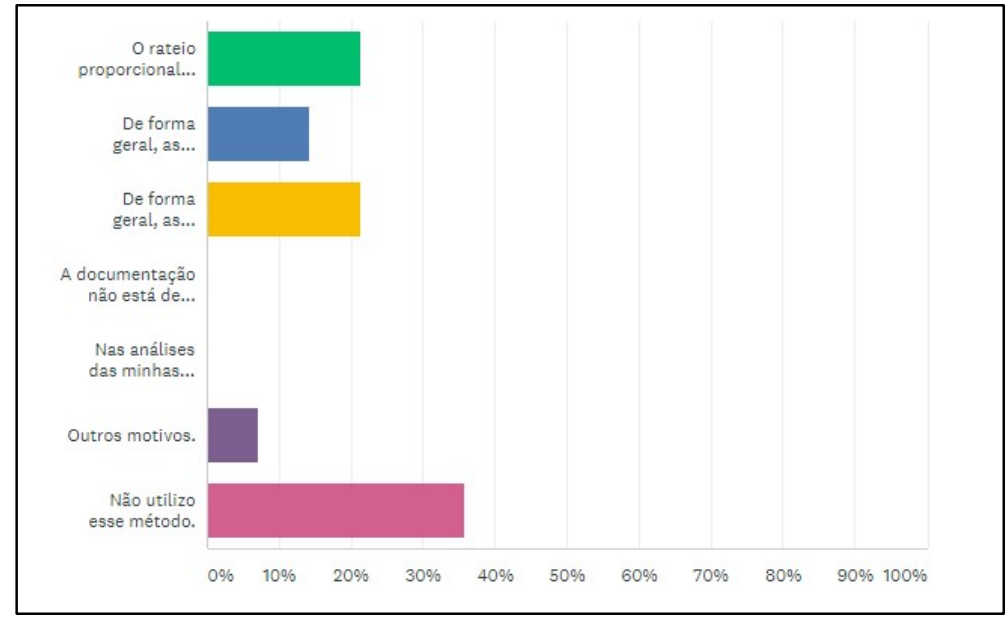

Figura 4: Resultado do questionário.

Em relação aos motivos para a utilização do método da apropriação direta pela contabilidade de custos na apropriação do direito ao crédito do PIS/Pasep e da Cofins, do total de respondentes, as respostas seguiram conforme o gráfico:

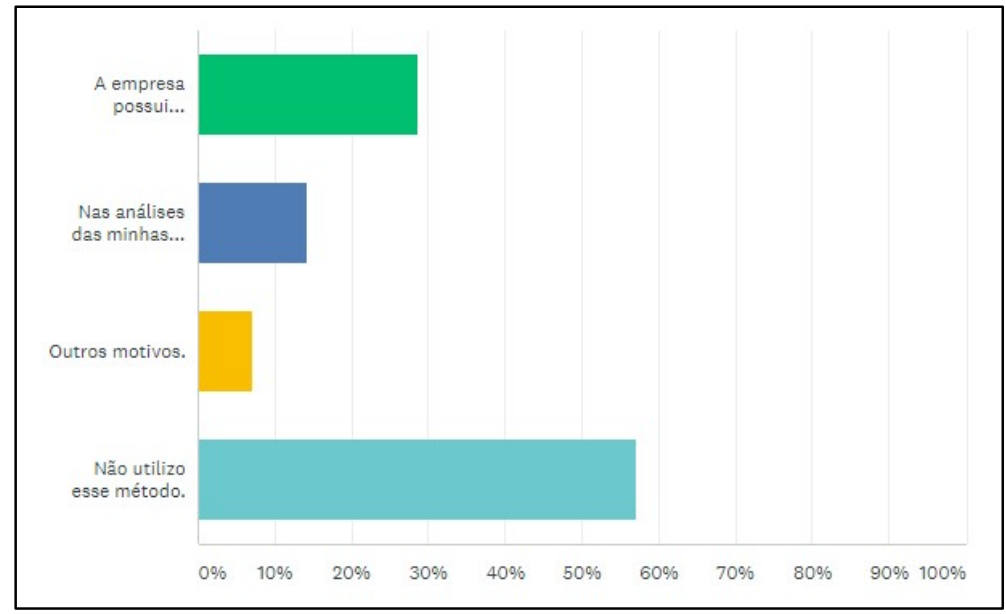

Figura 5: Resultado do questionário.

Do total de respondentes, $29 \%$ afirmam que utilizam o método porque as empresas mantêm contabilidade que condiz com a realidade dos custos existes e possuem os documentos necessários para comprovação por esse método; $14 \%$ afirmam que esse método é mais vantajoso do que o método de rateio proporcional e $7 \%$ utiliza por outros motivos, não listados. Pouco mais de $57 \%$ dos respondentes não utiliza 
esse método.

\section{Análise dos resultados}

Do total de 24 possíveis respondentes, 14 retornaram os questionários, sendo que $57 \%$ destes não fazem a contabilidade de nenhuma empresa enquadrada na situação do estudo, ou seja, que tenha por regime tributário o Lucro Real e que, simultaneamente, possuam a apuração cumulativa e não cumulativa dentro da mesma empresa, conforme o artigo 10 da Lei no 10.833/03, para a apuração do PIS/Pasep e Cofins.

Apesar dos grupos de natureza de atividades que se encaixam nesse regime simultâneo de cumulatividade e não cumulatividade na apuração dos créditos serem restritos a situações bem específicas, como hotéis com restaurante, escolas com vendas de livros, ou seja, comércio atrelado à prestação de serviços que englobem atividades cumulativas e não cumulativas, o índice de respondentes que não têm contato com nenhuma empresa na situação foi alto.

Considerando que a maior parte dos questionados representam escritórios de contabilidade - e isso aumenta as chances de contato com empresas na situação estudada, o alto índice de respostas para zero empresas na situação pode ser entendido de duas formas: ou as empresas que possuem essa particularidade na forma de apuração de créditos estão concentradas em outros escritórios que não os questionados, ou os profissionais que responderam às questões desconhecem a situação a ponto de não reconhecerem o enquadramento das empresas nessa especificidade e possibilidade de apuração de crédito.

Corrobora a segunda suposição o baixo índice de respondentes que afirmaram sentirem-se aptos para analisar todas as possibilidades de crédito de PIS/Pasep e da COFINS quando a mesma empresa possui atividades cumulativas e não cumulativas. Percebem-se parcialmente aptos $64 \%$ dos respondentes, em decorrência das legislações serem esparsas, imprecisas, das interpretações nos próprios processos de fiscalização serem divergentes. Esses fatores podem levar o profissional da contabilidade a sentir-se inseguro para avaliar e registrar, com segurança, os créditos tributários.

Quando questionados sobre o critério de escolha do método ser sempre o mesmo para todas as empresas em que atuam, metade dos respondentes afirmaram que não - ou seja, é feita uma avaliação das vantagens de cada método, empresa a empresa. A outra metade é fiel a um critério de escolha: 14\% à apropriação direta e $36 \%$ ao rateio proporcional.

Profissionais de contabilidade afirmarem que sempre adotam o mesmo método, considerando que muitos trabalham em escritórios e cuidam de mais de uma empresa, significa dizer que não são feitas análises personalizadas acerca das vantagens para cada empresa, de forma individual. Cada organização é única, e o resultado da apuração dos créditos tributários pode variar de uma para outra. Tratar todas da mesma maneira pode significar créditos subestimados e gastos desnecessários em razão da desatenção às possibilidades de apuração. Como consequência, em escala maior, pode o mercado indicar preços superiores aos possíveis, se uma gestão tributária eficiente fosse implementada.

Dentre os que optam sempre pelo mesmo método, maioria afirmou utilizar o critério do rateio proporcional, ou seja, aplicar a relação percentual existente entre a receita bruta sujeita à incidência não- 
cumulativa e a receita bruta total, auferidas em cada mês, aos custos, despesas e encargos comuns. Assim, na maior parte dos casos, como o nome sugere, é feito um rateio dos custos em comum entre as atividades cumulativas e não cumulativas, com base na receita bruta de cada atividade.

Os motivos para a utilização desse método se concentram na maior agilidade na apuração do crédito - visto que que é um rateio simples; no fato de que, de forma geral, as empresas não possuem contabilidade de custos integrada e coordenada com a escrituração adequada à realidade; ou mesmo, simplesmente, as empresas não possuem contabilidade de custos, o que inviabiliza a aplicação do método da apropriação direta. Nenhum dos respondentes que utilizam sempre o rateio proporcional afirmou adotá-lo por esse ser o método que traz mais vantagens em relação aos créditos apurados.

Nesse sentido, a adoção do método do rateio proporcional parece ser majoritária não porque é mais vantajosa em resultado de créditos apurados, mas por ser mais prática e facilmente aplicada às empresas que não mantêm controle de custos. A utilização é basicamente por exclusão. Talvez se as empresas mantivessem contabilidade de custos compatível com a realidade, o resultado fosse diferente.

Entre os que utilizam o método da apropriação direta pela contabilidade de custos, a maior parte o utiliza porque a empresa mantém o controle de custos condizente com a realidade e possui a documentação necessária para comprovação, caso necessário. Apenas dois respondentes firmaram que, em análise às empresas, o direito ao crédito pela contabilidade de custos é maior do que pelo rateio proporcional. Do total de respondentes, significa dizer que pouco mais de $14 \%$ leva em consideração a vantagem tributária de cada método. Isso representa também $14 \%$ da amostra.

Os dados coletados se referem, em sua maioria, a informações de profissionais que trabalham em escritórios de contabilidade no estado de Santa Catarina (SC). No entanto, essa regionalização dos respondentes não significa que apenas empresas da região de SC foram incluídas no estudo. No total, foram avaliadas as escolhas pelos métodos de apropriação direta ou rateio proporcional de 14 empresas, espalhadas por todas as regiões do Brasil.

\section{CONCLUSÕES}

Esse estudo procurou conhecer qual é o método predominantemente utilizado pelas pessoas jurídicas parcialmente submetidas à não cumulatividade na apuração do PIS/Pasep e da Cofins, e entender o motivo dessa escolha. A metade dos respondentes afirmou avaliar as vantagens e desvantagens de cada método, para cada empresa. A outra metade, que sempre utiliza o mesmo método, opta por utilizar o método do rateio proporcional. Os motivos que os levam a adoção desse método vão desde a agilidade na aplicação até a carência de informações de custos para sustentar a aplicação da apropriação direta pela contabilidade de custos. Nenhum dos respondentes afirmou fazer uma análise de benefícios entre um método e outro. Esse resultado indica que, aparentemente, a utilização do rateio se dá mais por exclusão do que por vantajosidade do método.

A legislação tributária e a contabilidade gerencial, muitas vezes, andam distantes. Isso é demonstrado desde o método de custeio aceitável fiscalmente não ser necessariamente o que traz mais riqueza de 
informações para as empresas, até o fato de que as próprias empresas e contadores responsáveis não fazerem uso, de forma geral, de informações gerenciais e de contabilidade de custos para a tomada de decisão mais eficiente em relação à apuração de créditos tributários.

Nessa mesma linha, a pesquisa indicou que mais de $60 \%$ dos profissionais responsáveis pela contabilidade não se sentem totalmente aptos para analisar todas as possibilidades de crédito de PIS/Pasep e COFINS quando, simultaneamente, a empresa possui atividades cumulativas e não cumulativas. Isso ocorre devido a quantidade de legislação relacionada e falta de interpretação única do processo (diferentes regiões com diferentes interpretações sobre o mesmo assunto).

Corrobora com essa insegurança o indicativo de que 35\% dos participantes alegarem que a contabilidade existente não é apta para essa análise, ou seja, os profissionais não confiam na contabilidade de custos das empresas para um enquadramento fiscal. Os resultados demonstram que, apesar de ser obrigatória a manutenção de contabilidade que demonstre a realidade da empresa, não necessariamente ela é utilizada quando o foco é a tributação.

Mesmo com amostra reduzida, essa pesquisa alcançou dados de pelo menos uma empresa de cada região brasileira. Como limitações, destaca-se o número baixo de empresas que responderam ao questionário e que se encontram nessa situação. A informação de quantidade de empresas que optam pelo Lucro Real e se enquadram na situação estudada não existe de forma pública, o que dificulta também a análise com amostrar mais representativa.

Como recomendações para estudos futuros, sugere-se definir uma amostra de empresas que se enquadram nessa situação de enquadramento no Lucro Real e simultaneidade de atividades cumulativas e não cumulativas, que mantenham contabilidade de custos estruturada e investigar as situações em que um método se mostra mais vantajoso que outro. Outra pesquisa que enriqueceria os estudos na área é investigar se a maioria das empresas de fato aplica a utilização de créditos tributários nas atividades não cumulativas ou se essa possibilidade passa despercebida pelos profissionais responsáveis pela contabilidade.

\section{REFERÊNCIAS}

ALVARES, A.. Lucratividade de clientes: a utilização do custeio baseado em atividades e tempo sob enfoque do custo para servir aplicado numa empresa do setor alimentício. 2011

BRASIL. Constituição da República Federativa do Brasil de 1988. Brasília: DOU, 1988.

FERRAZ JUNIOR, T. S.. Agências reguladoras: legalidade e constitucionalidade. Revista Tributária e de Finanças Públicas, v.35, p.144-158, 2000

GIL, A. C.. Métodos e técnicas de pesquisa social. 5 ed. São Paulo: Atlas, 1999.

IFAC. International Federation of Accountants. Management accounting concepts. 1998.
KAPLAN, R. S.; COOPER, R.. Measure cost right: make the right decisions. Harvard Business Review, p.8, 1988.

MARTINS, E.. Contabilidade de custos. 9 ed. São Paulo: Atlas, 2008.

MILLER, J. G.; VOLLMANN, T. E.. The Hidden Factory. Harvard Business Review, v.63, n.5, p.142, 1985.

PADOVEZE, C. L.. Contabilidade gerencial: um enfoque em sistema de informação contábil. 6. ed. São Paulo: Atlas, 2009.

SOUZA, M. A.. Mensuração e custeio: fundamentos de custos para gestão. In: PARISI, C.; MEGLIORINI, E. Contabilidade gerencial. São Paulo: Atlas, 2011. 